\title{
Synthesis and characterization of hydrogenated poly[alkylmethacrylate(-b- styrene)-b-butadiene-b-(styrene-b-) alkylmethacrylate] triblock and pentablock copolymers
}

\author{
Jian Ming Yu, Yisong Yu, Philippe Dubois, Philippe Teyssié, Robert Jérôme
}

University of Liège, Center for Education and Research on Macromolecules, Sart- Tilman, B6, 4000 Liège, Belgium

\begin{abstract}
Triblock and pentablock copolymers of the $\mathrm{X}(\mathrm{Y}) \mathrm{B}(\mathrm{Y}) \mathrm{X}$ type have been synthesized by the sequential living anionic polymerization of butadiene (B), styrene (Y) and alkylmethacrylate $(\mathrm{X})$, respectively. The diadduct of tBuLi onto $m$-diisopropenylbenzene ( $m$-DIB) has been used as a difunctional initiator. Methylmethacrylate (MMA), $t$-butylmethacrylate (tBMA) and isobornylmethacrylate (IBMA) have been used as precursors of the outerblocks X. The polybutadiene (PBD) midblock that contains $c a 42-45 \%$ 1,2-units has been selectively hydrogenated into a saturated poly(ethylene-co-1-butene) (PEB) block. The homogeneous hydrogenation catalysis has no deleterious effect on the copolymer integrity. These completely soluble thermoplastic elastomers have been characterized by $F T$ i.r., n.m.r., d.s.c. and d.m.a. The PEB midblock has a low $T_{\mathrm{g}}\left(-50^{\circ} \mathrm{C}\right)$ and a small propensity to crystallize. The effect of hydrogenation on the morphology and mechanical properties depends on the outer block. Upon hydrogenation of the PBD midblock in polymethylmethacrylate (PMMA) and polyisobornylmethacrylate (PIBMA) containing triblock copolymers, the ultimate tensile strength is increased (except for a hard block content $>50 \%$ ) due to a sharper phase separation, whereas the elongation at break is decreased. The extent of phase separation is reduced in polyt-butylmethacrylate(PtBMA) containing triblock copolymers upon hydrogenation and the ultimate tensile strength is slightly decreased. Stereocomplexation of the syndiotactic PMMA outerblocks is observed to occur upon blending with isotactic PMMA
\end{abstract}

Keywords: thermoplastic elastomers; hydrogenation; polyalkylmethacrylate; stereocomplexation

\section{INTRODUCTION}

Thermoplastic elastomers have the unique property to be cross-linked in a spontaneous and thermoreversible manner. This remarkable behaviour has been extensively studied since the discovery of the styrene-butadienestyrene triblock copolymers (SBS). These materials consist of a network of flexible chains stabilized by polystyrene (PS) microdomains dispersed in a rubbery polybutadiene (PBD) matrix. This particular phase morphology is thus at the origin of a vulcanization process that, however, preserves the facility of the thermoplastic material for being processed. Tensile strength of thermoplastic elastomers essentially depends on the ability of the hard blocks to maintain a plastic deformation under stress. Tensile strength actually decreases sharply as the glass transition temperature $\left(T_{\mathrm{g}}\right)$ of the hard block is approached. The upper service temperature of SBS is accordingly limited to $c a 70^{\circ} \mathrm{C}$. It is very desirable to increase this upper limit and to widen the service temperature range so as to approach the one of vulcanized rubbers [1-9]. Among several known examples [1-5], Morton et al. [1] have considered the use of poly( $\alpha$-methylstyrene), the $T_{\mathrm{g}}$ of which is higher than polystyrene by $70^{\circ} \mathrm{C}$. The low ceiling temperature of this polymer, however, makes the synthesis of the triblock copolymer less attractive. Polyethylene sulfide [2] has also been explored as a substitute for polystyrene, but the related triblock copolymers have poor ultimate mechanical properties compared to SBS.

Polymethylmethacrylate (PMMA) is a candidate for the hard block, since the $T_{\mathrm{g}}$ of syndiotactic PMMA (sPMMA) $\left(125^{\circ} \mathrm{C}\right)$ is higher than polystyrene. Furthermore, PMMA is more polar than PS which is expected to increase the immiscibility with the PBD midblock and thus to improve the phase separation. Finally, sPMMA has the additional advantage of forming a stereocomplex with isotactic PMMA (iPMMA), the melting temperature of which may be as high as $190^{\circ} \mathrm{C}[6,7]$.

Recently, we have reported the synthesis and characterization of well defined triblock copolymers consisting of sPMMA blocks associated with a central PBD block [23]. These copolymers have been prepared by sequential living anionic polymerization of butadiene and MMA by using a difunctional initiator soluble in hydrocarbons. They have excellent mechanical performances. However, the poor resistance of the unsaturated PBD blocks 
when exposed to high temperature in air and to u.v. irradiation is a limitation for practical applications. This problem has been alleviated by the selective hydrogenation of the PBD block with formation of a polyolefin block known for resistance to thermo- and photo-oxidation [8]. For this reason, hydrogenation of polydiene and styrene-diene copolymers has been extensively studied [8-13], and particularly discussed in two recent reviews by Schulz [11] and McManus [13]. Only a few papers have focused on the hydrogenation of alkylmethacrylatediene copolymers [14-16].

The microstructure of polybutadiene synthesized by anionic polymerization is strongly dependent on the solvent polarity. Indeed, the content of 1,2-units increases from 10 to $85 \%$ when the solvent polarity is increased [28]. Therefore, hydrogenation of PBD yields an ethylene and 1-butene copolymer, the composition of which depends on the original PBD microstructure. In this work, 42-45\% 1,2-units has been envisioned in order to prevent efficiently the hydrogenated counterpart from crystallizing. Diethyl ether has accordingly been added to cyclohexane as a cosolvent.

This paper will report on the hydrogenation of butadiene and alkylmethacrylate containing thermoplastic elastomers and on the main properties of these hydrogenated materials. In addition to sPMMA, poly- $t$ butylmethacrylate $\left(T_{\mathrm{g}}=110^{\circ} \mathrm{C}\right)$ and polyisobornyl-methacrylate $\left(T_{\mathrm{g}}=190^{\circ} \mathrm{C}\right)$ have been associated with PBD and, in some cases, a PS block has been inserted between the polyalkylmethacrylate and the PBD blocks.

\section{EXPERIMENTAL}

\section{Materials}

Cyclohexane and diethylether were dried over $\mathrm{CaH}_{2}$ for $24 \mathrm{~h}$. THF was purified by refluxing over the deep purple sodium-benzophenone complex. All the solvents were further distilled from polystyryllithium under reduced pressure immediately before use. tert-Butyl-lithium (t-BuLi) (Aldrich, 1.3 M solution in cyclohexane) was diluted with cyclohexane and the final concentration $(0.2 \mathrm{~N})$ was determined by double titration [20], metaDiisopropenylbenzene (m-DIB, Aldrich) was dried over $\mathrm{CaH}_{2}$ for $24 \mathrm{~h}$, and finally distilled from fluorenyllithium before use. 1,1-Diphenylethylene (DPE, Aldrich) was dried over sec-BuLi and distilled from diphenylmethyl-lithium before use. Butadiene was dried over $n$-butyl-lithium at $-78^{\circ} \mathrm{C}$ without polymerizing. Styrene, methylmethacrylate (MMA), $t$-butylmethacrylate (tBMA) (Aldrich) and isobornylmethacrylate (IBMA) (Across Chimica) were distilled from $\mathrm{CaH}_{2}$ under reduced pressure and stored under nitrogen at $-20^{\circ} \mathrm{C}$. Before polymerization, MMA was added with a $10 \mathrm{wt} \% \mathrm{AlEt}_{3}$ solution in hexane until a persistent yellowish green colour was observed. It was then redistilled under reduced pressure just prior to use. Styrene was distilled from fluorenyllithium without polymerizing. tBMA and IBMA were distilled from a mixture of diisobutyl aluminum hydride (DIBAH: 0.1 M in toluene) and triethylaluminium (TEA: $0.1 \mathrm{M}$ in toluene) (50/50, v/v) [21].

\section{Block copolymerization}

Polymerization was carried out in a previously flamed 2-1 round-bottomed flask equipped with a magnetic stirrer under a dry nitrogen atmosphere. Syringes and stainless steel capillaries were used in order to transfer solvents, monomers and initiator. Details of the experimental techniques and reaction conditions were reported elsewhere $[23,29]$. The triblock copolymerization consisted of 3 steps: (1) butadiene was polymerized in a cyclohexane/diethyl ether mixture $(100 / 6, \mathrm{v} / \mathrm{v})$ at room temperature for one night, using a diadduct of m-DIB and two equivalents of t-BuLi (deep red colour) as a difunctional initiator previously prepared in cyclohexane at $50^{\circ} \mathrm{C}$ for $2 \mathrm{~h}$; (2) end-capping of PBD dianions by diphenylethylene (DPE) at room temperature for $1 \mathrm{~h}$; (3) addition of THF to cyclohexane $(40 / 60, \mathrm{v} / \mathrm{v})$ followed by alkylmethacrylate at $-78^{\circ} \mathrm{C}$. An additional step was necessary for the synthesis of pentablock copolymers, i.e. polymerization of styrene initiated by the PBD dianions at room temperature for $2 \mathrm{~h}$, followed by end-capping with DPE. When the polymerization of butadiene was complete, an aliquot of the polymer solution was picked out and protonically deactivated. The polymer formed was recovered by precipitation into methanol and used to characterize the PBD block. The same procedure was carried out for the SBS sequence in case of pentablock copolymer. The synthesized block copolymers are listed in Table 1. Block copolymers with PMMA or PIBMA as outerblocks were recovered by precipitation in methanol. Copolymers containing PtBMA blocks were precipitated in a methanol/ $\mathrm{H}_{2} \mathrm{O}(60 / 40$, $\mathrm{v} / \mathrm{v}$ ) mixture. All the copolymers were dried at room temperature for 2 days in vacuum. 
Table 1 Main characteristics of the triblock and pentablock copolymers synthesized in this work

\begin{tabular}{|c|c|c|c|c|c|c|c|}
\hline \multirow[t]{2}{*}{ Sample } & \multirow[t]{2}{*}{ Copolymer $^{a}$} & \multirow[t]{2}{*}{$M_{\mathrm{n}}^{b} \times 10^{-3}$} & \multicolumn{2}{|l|}{$\mathrm{PBD}^{c}$} & \multirow{2}{*}{$\begin{array}{l}\text { Polymethacrylate } \\
\text { content (wt } \%)\end{array}$} & \multirow[t]{2}{*}{$T_{\mathrm{g}} \mathrm{l}^{d}\left({ }^{\circ} \mathrm{C}\right)$} & \multirow{2}{*}{$\begin{array}{l}T_{\mathrm{g}} 2^{d} \\
\left({ }^{\circ} \mathrm{C}\right)\end{array}$} \\
\hline & & & $\overline{(w t \%)}$ & $1,2(\%)$ & & & \\
\hline$\overline{\mathrm{A} 1}$ & M-B-M & $13-69-13(95)$ & 73 & 42 & 27 & -62 & 110 \\
\hline $\mathrm{A} 2$ & M-B-M & $14-80-14(108)$ & 74 & 43 & 26 & -60 & 114 \\
\hline A3 & M-B-M & $15-58-17(92)$ & 63 & 44 & 37 & -61 & 115 \\
\hline A4 & M-B-M & $24-80-24(128)$ & 63 & 42 & 37 & -61 & 120 \\
\hline A5 & M-B-M & $50-100-50(200)$ & 50 & 45 & 50 & -60 & 129 \\
\hline A6 & M-S-B-S-M & $19-18-79-18-19(153)$ & 52 & 43 & 24 & -60 & 110 \\
\hline $\mathrm{B}$ & tBMA-B-tBMA & $13-70-13(96)$ & 73 & 43 & 27 & -58 & - \\
\hline $\mathrm{C}$ & IBMA-B-IBMA & $15-60-15(90)$ & 67 & 43 & 33 & -58 & - \\
\hline
\end{tabular}

${ }^{a} \mathrm{M}$, methylmethacrylate; $\mathrm{B}$, butadiene; S, styrene; tBMA, t-butylmethacrylate; IBMA, isobornylmethacrylate

${ }^{b}$ Measured by s.e.c. and ${ }^{1} \mathrm{H}$ n.m.r., values in parentheses are total $\mathrm{M}_{\mathrm{n}}$

${ }^{c}$ Measured by ${ }^{1} \mathrm{H}$ n.m.r.

${ }^{\mathrm{d}}$ Measured by d.s.c. at a heating rate of $20^{\circ} \mathrm{C} \mathrm{min}^{-1}$

\section{Hydrogenation}

A triethyl aluminium/cobalt 2-ethyl hexanoate complex was used as homogeneous hydrogenation catalyst [10]. This complex was prepared by adding dropwise the transition metal salt ( $0.2 \mathrm{M}$ in toluene) to the metal alkyl (1 $\mathrm{M}$ in toluene) under nitrogen. The metal alkyl/metal salt molar ratio was usually $3 / 1$. Hydrogenation was conducted in a 5-1 autoclave, equipped with a mechanical stirrer. The copolymer was previously dried by 3 azeotropic distillations of toluene, then dissolved in dry toluene ( $0.7 \mathrm{wt} \%$ copolymer $)$ and finally added with the catalytic complex (usually ca $0.03 \mathrm{~mol}$ of transition metal per mol of double bond). This reactive mixture was added into the reactor, which was then closed and purged with nitrogen. The reactor was heated to $60^{\circ} \mathrm{C}$, purged with hydrogen and the hydrogen pressure was increased up to 6 bar. Five hours later, the catalyst was deactivated by addition of dilute $\mathrm{HCl}$. The copolymer was precipitated in methanol, washed and redissolved in toluene, reprecipitated and dried under vacuum.

\section{Film preparation}

Block copolymers were added with $1 \mathrm{wt} \%$ hindered phenol antioxidant (tetrakis[methylene 3-(3',5'-di-t-butyl-4'hydroxylphenyl) propionate] methane, Irganox 1010, Ciba-Geigy Corp.) and dissolved in toluene at room temperature. In the case of stereocomplexation, block copolymer and iPMMA were separately dissolved in toluene at room temperature. The solutions were then mixed at $100^{\circ} \mathrm{C}$, since mixing at room temperature immediately resulted in a gel. This homogeneous solution ( $8 \mathrm{wt} \%$ copolymer) was poured into a Petri dish and the solvent was let to evaporate slowly over 3-4 days at room temperature. Films were dried to constant weight in a vacuum oven at $40^{\circ} \mathrm{C}$. They were elastomeric and transparent with a smooth surface.

\section{Analysis}

Molecular weight and molecular weight distribution were measured by size exclusion chromatography (s.e.c.) with a Waters GPC 501 apparatus equipped with linear styragel columns. THF was the eluent (flow rate of $1 \mathrm{mlmin}^{-1}$ ) and polystyrene standards were used for calibration.

${ }^{1} \mathrm{H}$ n.m.r. spectra were recorded with a Brucker AM-400 spectrometer, using $\mathrm{CDCl}_{3}$ as a solvent at $25^{\circ} \mathrm{C}$. The 1,2-unit content of PBD was calculated from the relative intensity of the signal at $4.9 \mathrm{ppm}\left(=\mathrm{CH}_{2}\right.$ of 1 ,2-double bond $)$ and the signal at 5.4ppm $(\mathrm{CH}=$ of 1,2-double bond and $-\mathrm{CH}=\mathrm{CH}-$ of 1,4 unit). The copolymer composition was calculated from the relative intensity of the 1,2-unit in PBD, the signals for the phenyl ring in PS (6.5 and $7.1 \mathrm{ppm})$ and the signal of the $\mathrm{O}-\mathrm{CH} 3$ group in PMMA $(3.54 \mathrm{ppm})$ or the $0-\mathrm{CH}<(4.35 \mathrm{ppm})$ in PIBMA. In the case of PtBMA, the overlapping of the signal for the $\mathrm{O}-\mathrm{C}\left(\mathrm{CH}_{3}\right)_{3}$ prevents any composition analysis from being quantitative. The composition was then estimated from the initial monomer amount and monomer conversion. $\mathrm{M}_{\mathrm{n}}$ for the PS and polyalkylmethacrylate blocks was calculated from the copolymer composition and PBD molecular weight.

The degree of hydrogenation was calculated by ${ }^{1} \mathrm{H}$ n.m.r. by comparing the spectra before and after hydrogenation.

Differential scanning calorimetry (d.s.c.) was carried out with a DuPont 900 instrument, calibrated with indium. The heating rate was $20^{\circ} \mathrm{C} \mathrm{min}^{-1}$, and the glass transition temperature was noted at the inflection point of the heat 
capacity jump.

Dynamic mechanical analysis (d.m.a.) was carried out with a TA 983 Dynamic Mechanical Analyzer. Samples $\left(8 \times 10 \times 0.5 \mathrm{~mm}^{3}\right)$ were deformed at a constant $1 \mathrm{~Hz}$ frequency.

Tensile measurements were conducted with an Adamel Lhomargy tensile tester. Microdumbell shaped testing samples were cut from toluene cast films and extended at $200 \mathrm{~mm} \mathrm{~min}^{-1}$ at room temperature. The reported data were average values of three measurements.

I.r. spectra for toluene cast films were recorded with the 600 FT i.r. Perkin-Elmer spectrometer.

\section{RESULTS AND DISCUSSION}

Synthesis of block copolymers

It has been reported from our laboratory [23] that well defined triblock copolymers could be obtained by sequential living anionic polymerization of butadiene and methyl methacrylate (MMA) with the $t$-butyllithium (t-BuLi)/m-diisopropenyl benzene diadduct as a difunctional initiator.
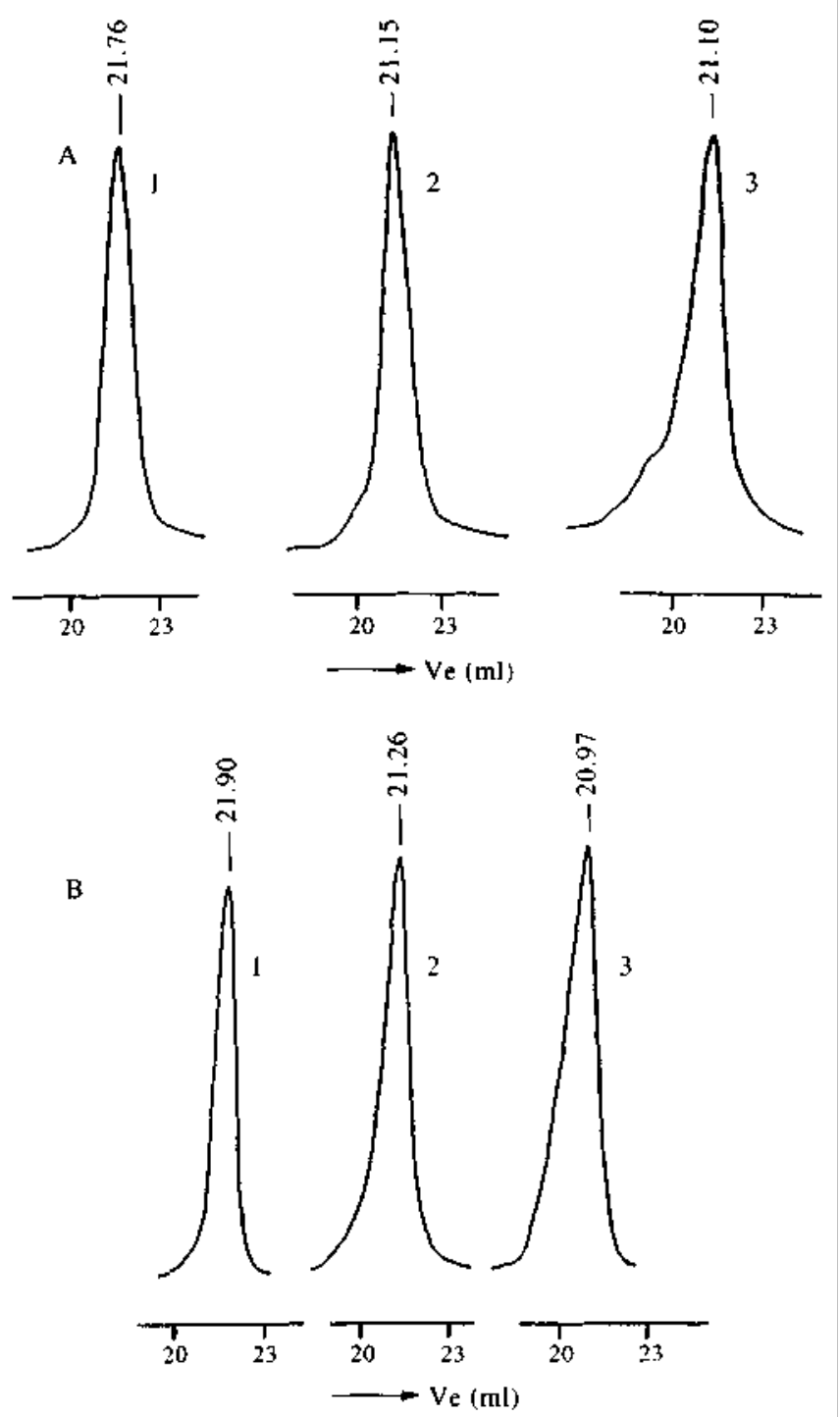

Figure 1 S.e.c. traces of PBD midblock (1), MBM (SBS) triblock (2) and MSBSM pentablock (3) for samples A1 (A) and A6 (B). Trace 3(A) is for the hydrogenated Al copolymer, i.e. sample HA1 


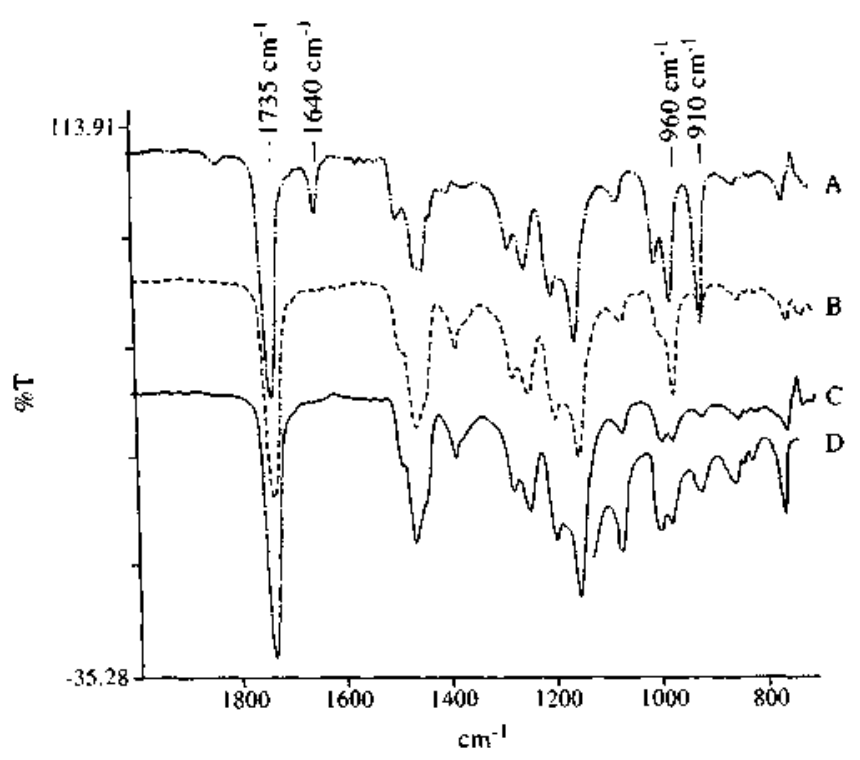

Figure 2 FT i.r. spectra for the original MBM triblock copolymer A4 (A), the 60\% hydrogenated A4 copolymer (B), the completely hydrogenated sample HA4 (C) and a homo PMMA (D)

This method was also successful for the preparation of pentablock copolymers [26]. The same copolymerization technique has been used in this work and extended to other alkylmethacrylates than MMA, i.e. tBMA and IBMA. The polymerization medium forms a gel when MMA is polymerized in the case of the synthesis of poly(MMA-b-BD-b-MMA) (MBM) triblocks and poly(MMA-b-S-b-BD-b-S-b-MMA) (MSBSM) pentablock copolymers. No gelation is, however, observed when tBMA and IBMA are substituted for MMA, more likely because of the bulkiness of the tertiary butyl and isobornyl ester groups which hinders the mutual association of the methacrylate anions. When a gel is formed, it however dissolves upon the deactivation of the active species and warming up to room temperature. Table 1 lists the triblock and pentablock copolymers synthesized in this work, together with their molecular characteristic features and glass transition temperatures $\left(T_{\mathrm{g}}\right)$. All these block copolymers are of a very narrow molecular weight distribution $(\mathrm{MWD}=\mathrm{ca} .1 .1)$. Figure 1 shows typical s.e.c. traces for the triblock A1 and the pentablock A6. The molecular weight distribution remains narrow and symmetric while going from the PBD block, to the SBS or MBM triblock and finally to the pentablock copolymer, which indicates that the cross-reactions from butadienyl anions (or styryl anions) to alkylmethacrylate are fast and quantitative. The microstructure of the PBD midblock is essentially the same, whatever the copolymers, i.e. 42-45\% 1,2-units as measured by ${ }^{1} \mathrm{H}$ n.m.r. This microstructure has been selected as an efficient means of preventing crystallization of the hydrogenated counterpart. Indeed, hydrogenation of exceeding amounts of 1,4-units results in polyethylenelike blocks long enough to crystallize and to restrict the elasticity of the central block. Conversely, an excess of hydrogenated 1,2-units substantially raises the $T_{g}$ which is undesirable. Thus a content of 40\% 1,2-unit is a good compromise to obtain a saturated midblock of a low enough $T_{\mathrm{g}}$ and good elastomeric properties [8].

\section{Hydrogenation}

Figure 2 compares the FT i.r. spectra for the original MBM triblock copolymer A4 (Figure $2 A$ ), the $60 \%$ hydrogenated sample (after $c a 1$ h hydrogenation) (Figure $2 B$ ) and the completely hydrogenated HA4 copolymer (after $\mathrm{ca} 4 \mathrm{~h}$ hydrogenation) (Table 2, Figure 2C). Figure $2 A$ shows the distinct absorptions for the 1,4-units, and the 1,2-units of PBD at $1640 \mathrm{~cm}^{-1}(\mathrm{C}=\mathrm{C}$ stretch of $\mathrm{cis} 1,4-$ units $), 960 \mathrm{~cm}^{-1}(\mathrm{CH}=\mathrm{CH}$ of trans 1,4-units) and $910 \mathrm{~cm}^{-1}$ (1,2-units), respectively. In the case of $60 \%$ hydrogenation, only the absorption of the trans 1,4 -units persists (Figure 2B), which indicates that the double bonds of cis 1,4-units and 1,2-units are much more reactive towards hydrogenation than the trans 1,4-units, possibly because of less steric hindrance. The same observation was reported for the hydrogenation of $\mathrm{PBD}$ in the presence of a soluble $\mathrm{Rh}$ catalyst [27]. After complete hydrogenation, the typical absorptions of $\mathrm{C}=\mathrm{C}$ double bonds at 1640,960 and $910 \mathrm{~cm}^{-1}$ are no longer observed (Figure 2C), the residual absorptions at 960 and $910 \mathrm{~cm}^{-1}$ being due to PMMA as shown by Figure $2 D$ for homoPMMA of the same molecular weight and tacticity as the PMMA end block. 
Table 2 Main characteristics of the hydrogenated block copolymers and blends with iPMMA

\begin{tabular}{|c|c|c|c|c|c|c|c|c|}
\hline Sample & Original copolymer & $\mathrm{M}_{\mathrm{w}} / \mathrm{M}_{\mathrm{n}}^{a}$ & $\begin{array}{l}T_{g l}^{b} \\
\left({ }^{\circ} \mathrm{C}\right)\end{array}$ & $T_{g} 2^{b}\left({ }^{\circ} \mathrm{C}\right)$ & $\begin{array}{l}\Delta H_{\mathrm{m}_{(\mathrm{PEB})}}^{b, c} \\
\left(\mathrm{~J} \mathrm{~g}^{-1} \mathrm{PEB}\right)\end{array}$ & $T_{\mathrm{m}} 1^{b}\left({ }^{\circ} \mathrm{C}\right)$ & $T_{\mathrm{m}} 2^{b}\left({ }^{\circ} \mathrm{C}\right)$ & $\begin{array}{l}\Delta H_{\mathrm{m}} 2^{b} \\
\left(\mathrm{~J} \mathrm{~g}^{-1} \text { PMMA }\right)\end{array}$ \\
\hline$\overline{\text { HA1 }}$ & $\mathrm{Al}$ & 1.15 & -52 & 113 & 14.0 & - & - & - \\
\hline HA2 & $\mathrm{A} 2$ & 1.20 & -52 & 118 & 12.8 & - & - & - \\
\hline HA3 & A3 & 1.20 & -54 & 125 & 13.6 & - & - & - \\
\hline HA4 & A4 & 1.15 & -52 & 127 & 13.5 & - & - & - \\
\hline HA5 & A5 & 1.15 & -45 & 135 & 12.0 & - & - & - \\
\hline HA6 & A6 & 1.20 & -50 & 112 & 16.0 & - & - & - \\
\hline HB & B & 1.15 & -45 & 一 & 13.7 & - & - & - \\
\hline $\mathrm{HC}$ & $\mathrm{C}$ & 1.15 & -50 & 一 & 14.5 & - & - & - \\
\hline CHA1 & HA1+iPMMA & - & -53 & - & 14.0 & 176 & - & 25 \\
\hline CHA2 & HA2+iPMMA & - & -54 & 一 & 11.0 & 178 & - & 26 \\
\hline CHA4 & HA4+iPMMA & - & -51 & 一 & 14.3 & 173 & 186 & 30 \\
\hline CHA5 & HA5+iPMMA & - & -44 & - & 13.2 & 178 & 184 & 40 \\
\hline
\end{tabular}

${ }^{a}$ S.e.c. with polystyrene standards for calibration

${ }^{b}$ D.s.c. heating rate: $20^{\circ} \mathrm{C} \mathrm{min}^{-1}$

c The endotherm is too broad for $\mathrm{T}_{\mathrm{m}}$ to be accurately determined

The butadiene double bonds can thus be quantitatively hydrogenated, whereas the carbonyl absorption at 1735 $\mathrm{cm}^{-1}$ remains unchanged. That PMMA is unaffected by the hydro-genation reaction has been confirmed by treating homoPMMA of the same tacticity and molecular weight as the sPMMA end block under the conditions used for hydrogenation. No modification in the ${ }^{1} \mathrm{H}$ and ${ }^{13} \mathrm{C}$ n.m.r. spectra can be detected as a result of this treatment. Quantitative conversion of the $\mathrm{C}=\mathrm{C}$ double bonds has also been confirmed by ${ }^{1} \mathrm{H}$ n.m.r., as shown in Figure 3 for the MBM triblock A4 and in Figure 4 for the MSBSM pentablock A6. The resonance peaks at 4.9 and $5.6 \mathrm{ppm}$ for the $-\mathrm{CH}=\mathrm{CH}_{2}$ 1,2-units and at $5.4 \mathrm{ppm}$ for the $-\mathrm{CH}=\mathrm{CH}-1,4$-units (Figures $3 \mathrm{~A}$ and $4 \mathrm{~A}$ ) have disappeared upon hydrogenation (Figures $3 \mathrm{~B}$ and $4 \mathrm{~B}$ ), in contrast to the signal at $3.6 \mathrm{ppm}$ for the $-\mathrm{OCH}_{3}$ ester protons (Figures $3 A$ and $B$ ) and the signal at 7 ppm for the phenyl proton (Figures $4 A$ and $B$ ) which remain unchanged. The molecular weight distribution is kept narrow after hydrogenation (1.15 against 1.10 before hydrogenation), as shown by s.e.c. traces (Figure 1A, trace 3). A small shoulder is observed on the high molecular weight side, the origin of which is not clear.

Figure 5 shows the methylene carbon regions of the ${ }^{13} \mathrm{C}$ n.m.r. spectrum for the MEBM sample HA4. The assignment of the resonance peaks relies upon data reported elsewhere for hydrogenated PBD of a comparable microstructure [22]. The signal 1 at $30.01 \mathrm{ppm}$ is typical of the methylene carbons of polyethylene sequences. The signals 2, 3 and 4 at 30.47(2), 27.04(3) and 33.48(4) ppm, respectively, are characteristic of the same methylene carbons but influenced by a butylene unit.

The signals 5 and 6 at 39.16(5), 26.17(6) ppm are assigned, respectively, to the methyne and to the methylene carbons of single butylene units and the signal 8 at $36.42 \mathrm{ppm}$ results from a dimeric (or longer) sequence of butylene units. The signal 7 at $30.91 \mathrm{ppm}$ is typical of one hydrogenated 1,4-unit between two butylene ones. The intensity of the resonance peaks for these carbon atoms can be compared since no tacticity effect is involved and the n.m.r. lines are quite narrow. From the comparison of the signal intensities with intensities predicted by Bernouilli statistics [22], the ethylene and butylene units appear to be randomly distributed, as it is the case of the hydrogenation of PBD synthesized with a monofunctional initiator instead of a difunctional one in this study. The quantitative hydrogenation of PtBMA-PBD-PtBMA and PIBMA-PBD-PIBMA triblock copolymers has also been ascertained by FTi.r., as shown in Figures 6 and 7. 
Published in: Polymer (1997), vol. 38, iss. 12, pp. 3091-3101

Status: Postprint (Author's version)

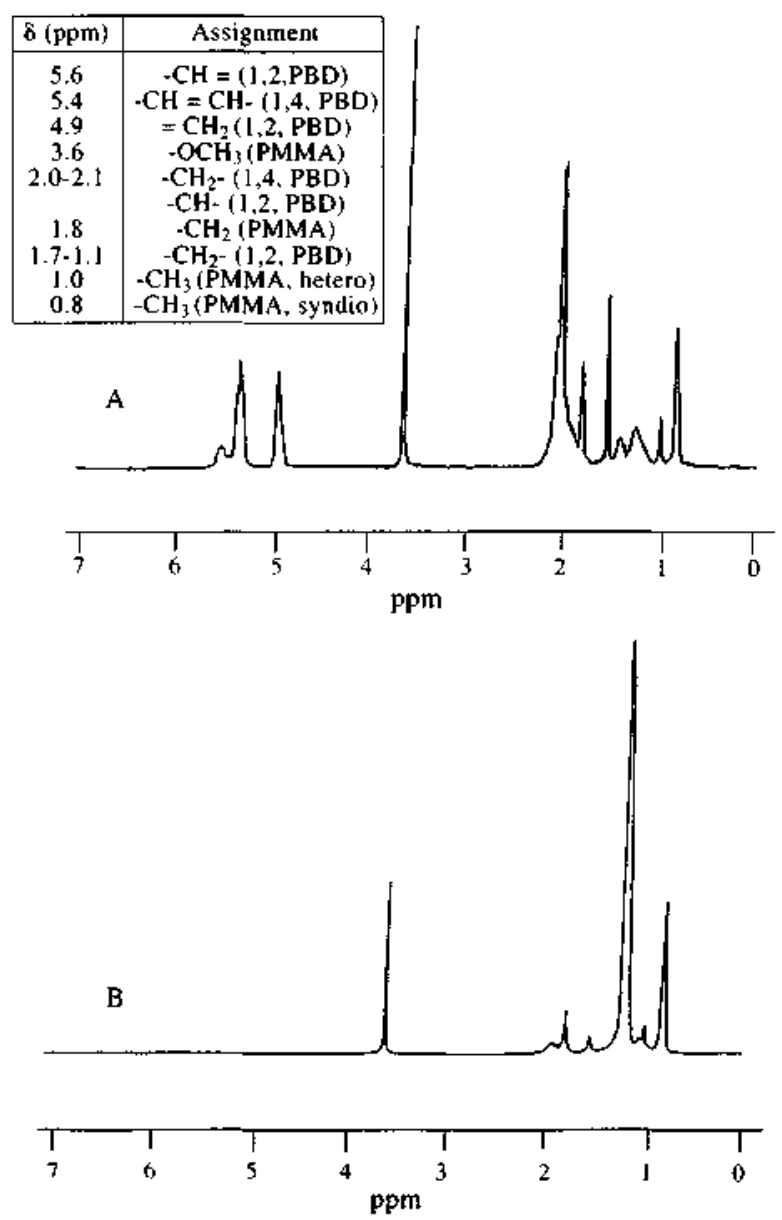

Figure $3400 \mathrm{MHz}{ }^{1}$ H n.m.r. spectrum for the original MBM triblock A4 (A) and the hydrogenated HA4 sample (B) in $\mathrm{CDCl}_{3}$ at $25^{\circ} \mathrm{C}$ 

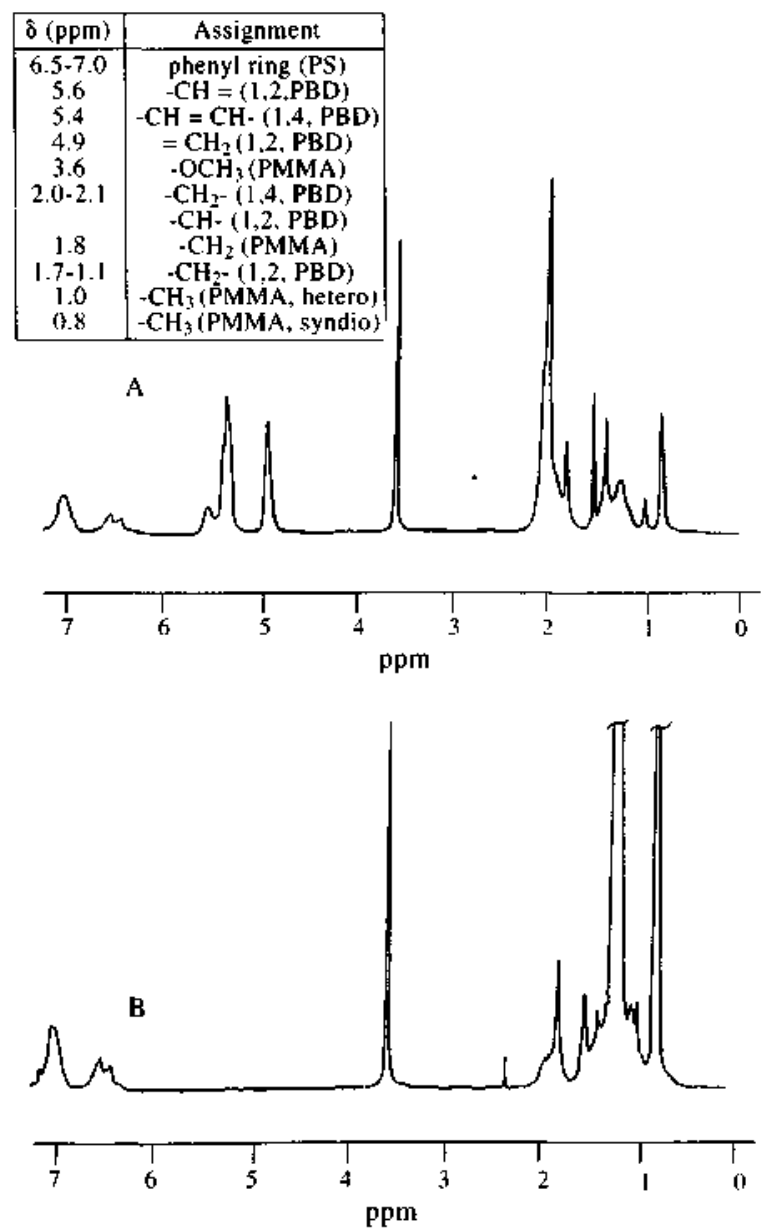

Figure $4400 \mathrm{MHz}{ }^{1} \mathrm{H}$ n.m.r. spectrum for the original MSBSM pentablock A6 (A) and the hydrogenated HA6 sample (B) in $\mathrm{CDCl}_{3}$ at $25^{\circ} \mathrm{C}$

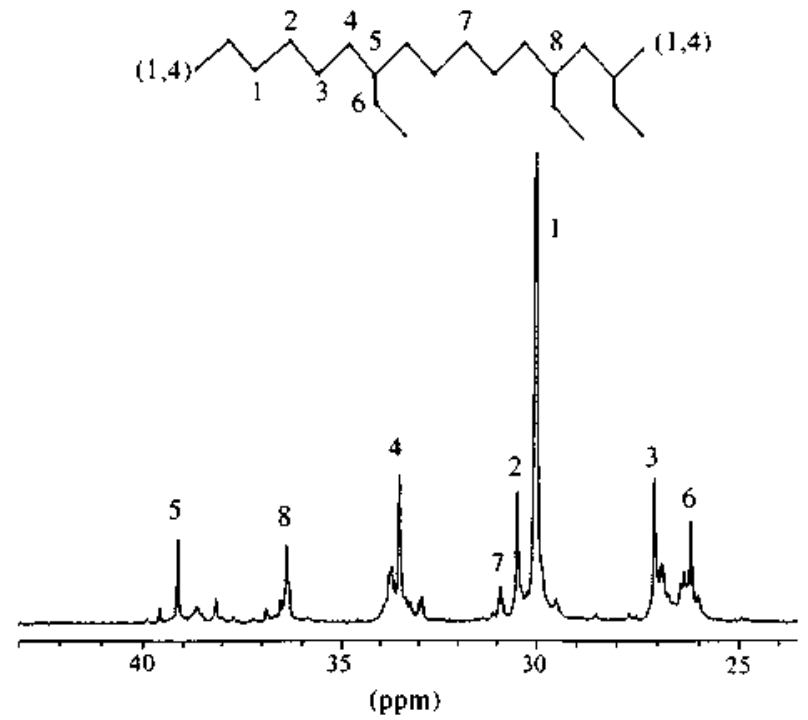

Figure 5 Partial $100 \mathrm{MHz}{ }^{13} \mathrm{C}$ n.m.r. spectrum for MEBM sample $\mathrm{HA} 4$ in $\mathrm{CDCl}_{3}$ at $25^{\circ} \mathrm{C}$ 


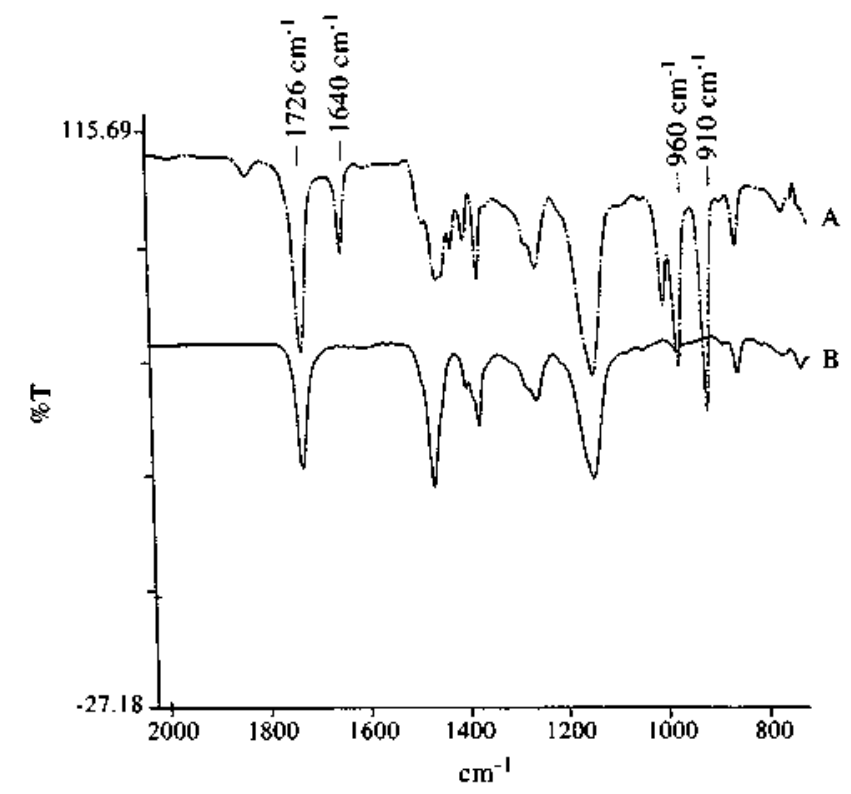

Figure 6 FT i.r. spectra for the original tBMA-PBD-tBMA triblock copolymer B (A) and the hydrogenated HB (B)

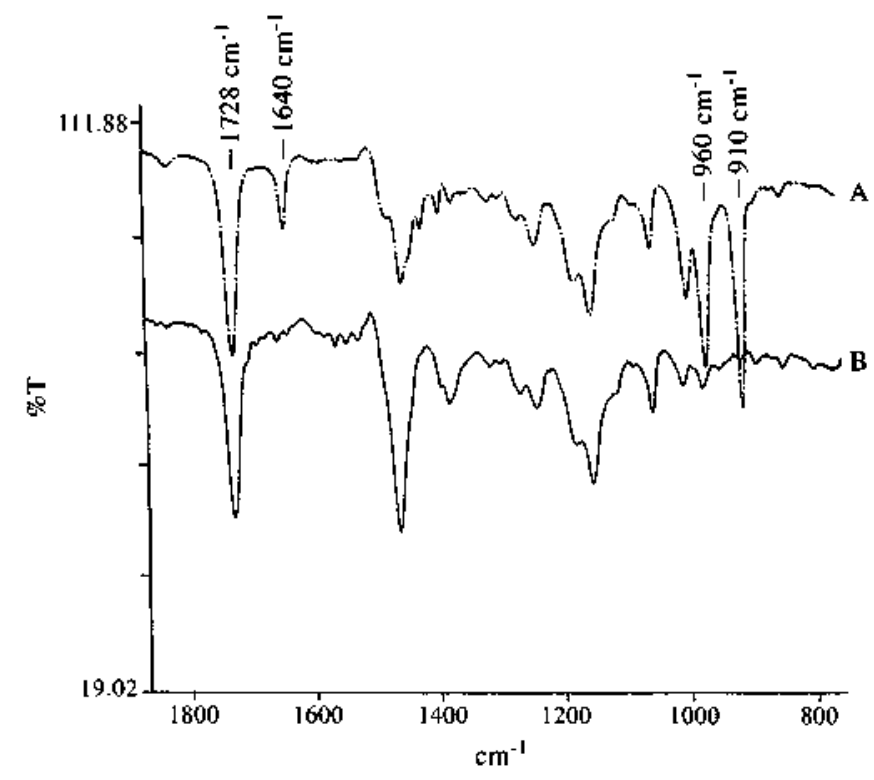

Figure 7 FT i.r. spectra for the original IBMA-PBD-IBMA triblock copolymer C (A) and the hydrogenated HC (B)

The i.r. absorption characteristic of the $\mathrm{C}=\mathrm{C}$ double bonds at 1640,960 and $910 \mathrm{~cm}^{-1}$ (Figures $6 A$ and $7 A$ ) have completely disappeared upon hydrogenation (Figures $6 B$ and $7 B$ ), whereas the carbonyl absorptions for PtBMA at $1726 \mathrm{~cm}^{-1}$ (Figure 6) and for PIBMA at $1728 \mathrm{~cm}^{-1}$ (Figure 7) remain unchanged, indicating that the ester group remains unaffected by hydrogenation, as in case of PMMA. It is worth noting that PtBMA [17] and PIBMA [18] are known to be easily hydrolysed in the presence of an acid and water. Although one component of the hydrogenation catalyst is a Lewis acid (triethyl aluminium), no hydrolysis of the ester group is observed, more likely due to the anhydrous conditions used for the hydrogenation. The narrow molecular weight distribution is preserved, as shown in Table 2 for samples HB and HC.

D.s.c. analysis

The d.s.c. traces reported for toluene cast films of the hydrogenated MBM and MSBSM block copolymers investigated in this study are essentially identical in shape and number of prominent features. $T_{\mathrm{g}} \mathrm{s}$ are listed in 
Table 1 for the original block copolymers and in Table 2 for the hydrogenated counterparts. Figure 8 compares the thermograms for the A4 triblock copolymer before and after hydrogenation. Two glass transition temperatures are observed for the soft $\left(T_{\mathrm{g}} 1\right)$ and the hard $\left(T_{\mathrm{g}} 2\right)$ microphases, respectively, indicating that these A4 and HA4 samples are phase separated. Since the hard block is minor (37 wt \%), it is not surprising that $T_{g} 2$ is not clearly observed. $T_{\mathrm{g}} \mathrm{l}$ for the hydrogenated sample $\left(-52^{\circ} \mathrm{C}\right.$ for HA4) is systematically higher than $T_{\mathrm{g}} \mathrm{l}$ for the original copolymer $\left(-61^{\circ} \mathrm{C}\right.$ for $\left.\mathrm{A} 4\right)$ which results from a change in the chemical structure and thus the flexibility of the soft block. In the case of sample HA4 (Figure 8), $T_{\mathrm{g}} 1$ is followed by a broad ill defined melting endotherm at higher temperature, which indicates that some poorly organized crystalline regions are formed in the poly(ethylene-co-1,2-butene), PEB, matrix. Short ethylene sequences observed by ${ }^{13} \mathrm{C}$ n.m.r. (Figure 5) are responsible for this behaviour, in good agreement with the observations reported for SEBS triblock copolymers [19]. As shown in Tables 1 and 2, $T_{\mathrm{g}} 2$ for the hydrogenated triblock copolymers (HA1-HA4) is higher than $T_{\mathrm{g}} 2$ for the original MBM copolymers, which is thought to result from a more complete phase separation.

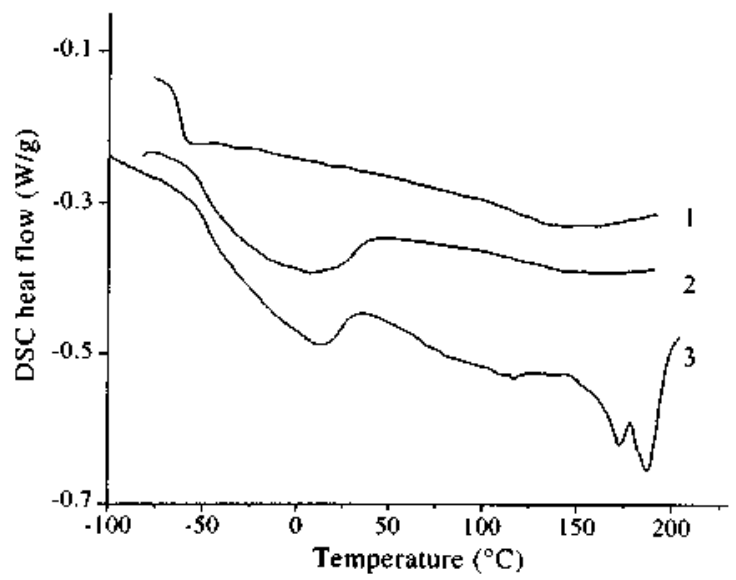

Figure 8 D.s.c. traces for the MBM triblock copolymer A4 (1), the hydrogenated HA4 sample (2), and the stereocomplex CHA4 sample (3). Heating rate: $20^{\circ} \mathrm{C} \mathrm{min}^{-1}$

The melting enthalpy $\left(\Delta H_{\mathrm{m}}\right)$ per gram of PEB calculated from the broad melting endotherm is also listed in Table 2. It seems to be essentially independent of the midblock molecular weight, and thus basically determined by the content of 1,2-units of the original PBD block. In the case of PtBMA and PIBMA containing triblock copolymers (samples B and C in Table 1 and samples HB, HC in Table 2), $T_{\mathrm{g}} 1$ for the soft phase is the same as for the MBM and MEBM copolymers, respectively, which is again consistent with a central block of the same microstructure in each series of copolymers (A, B, C). $T_{\mathrm{g}} 2$ for copolymers $\mathrm{B}, \mathrm{HB}, \mathrm{C}$ and $\mathrm{HC}$ is so diffuse that no reliable value can be reported. Stereocomplexation of MBM triblock copolymers with iPMMA has been reported to be efficient in extending the service temperature of the thermoplastic elastomers up to $180^{\circ} \mathrm{C}^{7}$. In order to confirm that stereocomplexation occurs independently of the hydrogenation of the PBD midblock, MEBM samples have been blended with isotactic PMMA (iPMMA) in a syndio/iso mixing ratio of 2/1, and films have been cast from toluene. Figure 8 (trace 3 ) shows a typical d.s.c. thermogram for the CHA4 sample (Table 2). In addition to the broad melting peak for the poorly organized crystalline domains of the PEB phase, better defined endotherms are observed below $200^{\circ} \mathrm{C}$, which correspond to the stereocomplex of the sPMMA end blocks with iPMMA. The melting endotherm for the stereocomplex formed by MEBM samples containing sPMMA blocks of various lengths is shown in Figure 9, and the melting temperatures are listed in Table 2. One melting peak is observed for the two samples with the shorter sPMMA block (CHA1 and CHA2: d.s.c. traces 1 and 2). Two peaks are observed for samples CHA4 and CHA5 (d.s.c. traces 3 and 4) that consist of higher molecular weight sPMMA block. In case of blends of iPMMA and sPMMA homopolymers of molecular weight higher than 19000, Challa et al. have usually observed two endotherms, that have been assigned to stereocomplexes organized into fringed-micellar clusters (low $T_{\mathrm{m}}$ ) and lamellae (high $T_{\mathrm{m}}$ ), respectively [6] . The melting enthalpy for the stereocomplexes seems to increase with sPMMA molecular weight and is quite comparable to the values reported for the unsaturated MBM counterparts blended with iPMMA [7]. 


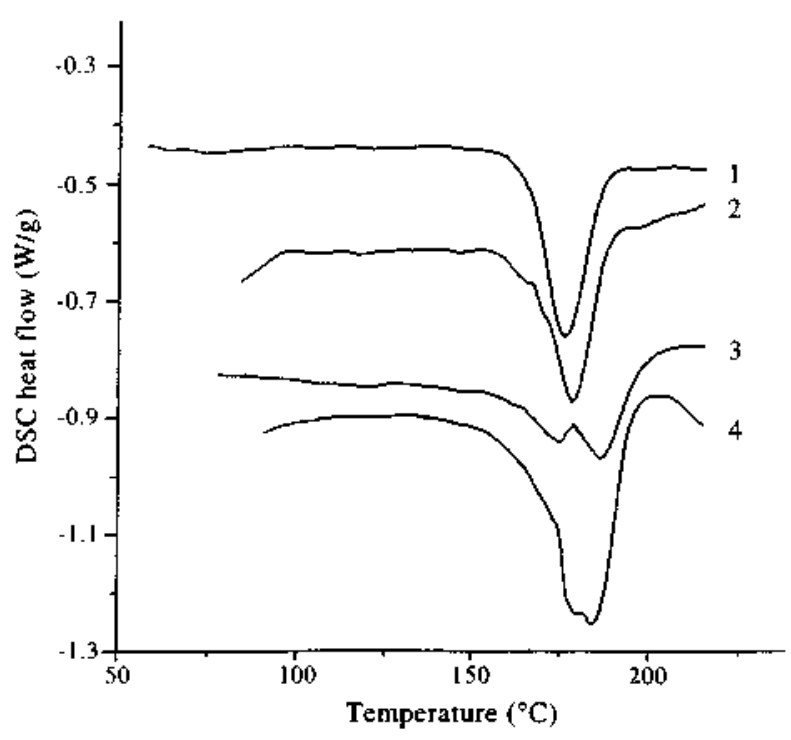

Figure 9 D.s.c. traces for the stereocomplexes of the MEBM copolymers with iPMMA: CHA1 (1), CHA2 (2), $\mathrm{CHA} 4$ (3) and CHA5 (4). Heating rate: $20^{\circ} \mathrm{C} \mathrm{min}^{-1}$

This indicates that the poorly crystallized PEB phase does not affect the stereocomplexation of the sPMMA end blocks with iPMMA. Furthermore, the melting enthalpy for the PEB soft phase remains unchanged when the sPMMA blocks are involved in stereocomplexes with iPMMA. Clearly, the phase separation is sharp enough for the two phases to crystallize quite independently of each other.

\section{D.m.a. analysis}

The thermal dependence of the dynamic shear storage modulus $\left(G^{\prime}\right)$ and loss $\tan \delta\left(=G^{\prime \prime} / G^{\prime}\right)$ has been analysed in the temperature range from -100 to $200^{\circ} \mathrm{C}$ at the $1 \mathrm{~Hz}$ frequency for copolymers before and after hydrogenation. Figures 10-13 confirm that all these copolymers are phase separated, since two transitions are clearly observed, which are characteristic of the glass transition for the PBD or PEB matrix at the lower temperature $\left(T_{g} 1\right)$ and for the dispersed hard phase at the higher temperature $\left(T_{g} 2\right)$. The temperature at each maximum of the tan $\delta$ curves is reported in Table 3. The storage modulus for the hydrogenated samples is lower compared to the original copolymer in the glassy region, whereas the reverse situation is observed in the rubbery plateau region. $T_{g} 1$ for the hydrogenated copolymer is higher than $T_{g} 1$ for the original copolymer, in agreement with d.s.c. analysis. Figure 10 illustrates the dynamic mechanical properties for the MBM copolymer A4, the hydrogenated counterpart HA4 and the blend with iPMMA (CHA4). The loss peak (Figure 10B) at the high temperature $\left(T_{\mathrm{g}} 2\right)$ is associated with $T_{\mathrm{g}}$ of the PMMA domains. It is shifted toward higher temperature upon hydrogenation, which might indicate a sharper phase separation. 
Published in: Polymer (1997), vol. 38, iss. 12, pp. 3091-3101

Status: Postprint (Author's version)

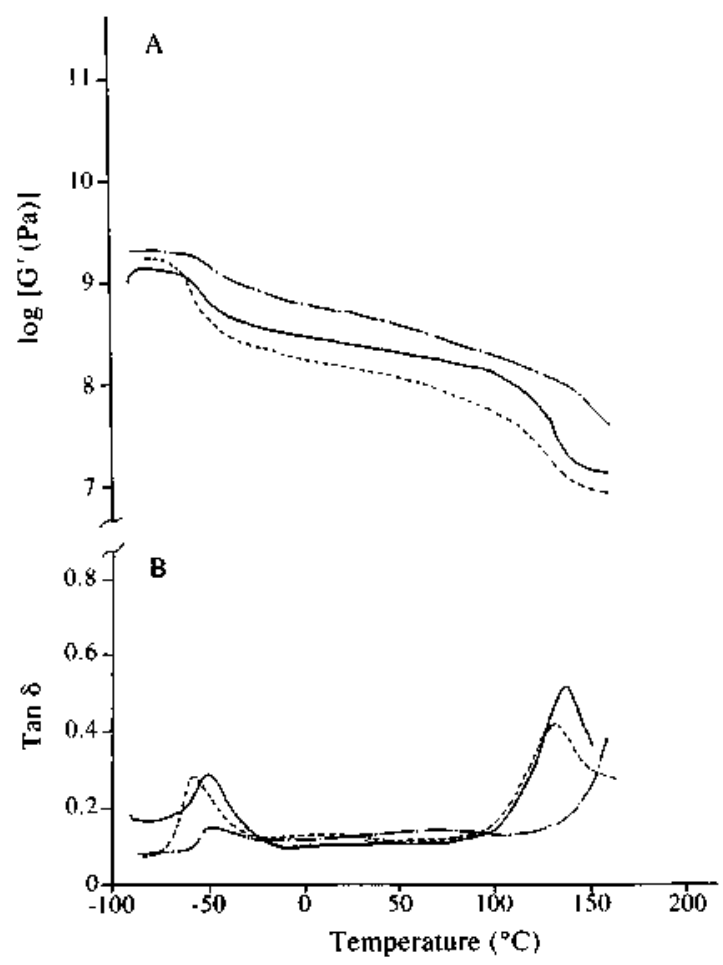

Figure 10 Shear storage modulus $\left(G^{\prime}\right)(A)$ and loss tan $\delta\left(=G^{\prime \prime} / G^{\prime}\right)(B)$ at 1 Hz for the MBM sample A4 (- - - -), the hydrogenated counterpart HA4 (-) and the stereocomplex sample CHA4 (- - - )

Table 3 Glass transition temperatures measured by dynamic mechanical analysis at $1 \mathrm{~Hz}$

\begin{tabular}{llll}
\hline Sample & $T_{\mathrm{g}} 1\left({ }^{\circ} \mathrm{C}\right)$ & $T_{\mathrm{g}} 2\left({ }^{\circ} \mathrm{C}\right)$ & Post transition $\left({ }^{\circ} \mathrm{C}\right)$ \\
\hline A4 & -57 & 130 & - \\
HA4 & -50 & 135 & - \\
HCA4 & -50 & - & $>160$ \\
A6 & -55 & 130 & - \\
HA6 & -49 & 128 & - \\
B & -50 & 116 & - \\
HB & -40 & 100 & - \\
C & -53 & 153 & - \\
HC & -46 & 180 & -
\end{tabular}




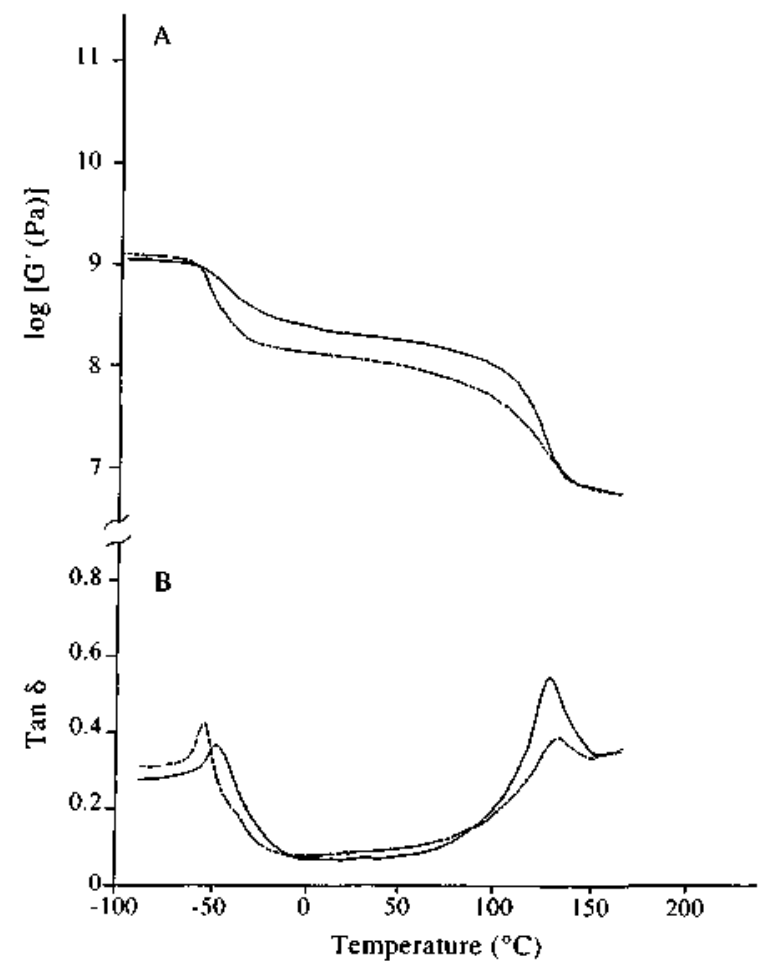

Figure 11 Shear storage modulus $\left(G^{\prime}\right)(A)$ and loss $\tan \delta\left(=G^{\prime \prime} / G^{\prime}\right)(B)$ at 1 Hz for the MSBSM sample A6 (- - -) and the hydrogenated counterpart HA6 (-)

This is confirmed by a more important damping for the HA4 compared to A4. It is worth recalling that hydrogenation of the SBS copolymers has been reported to enhance the upper service temperature by $\mathrm{ca} 20^{\circ} \mathrm{C}$ as result of a better phase separation [8]. This effect is comparatively less important in case of MBM copolymers $(<$ $10^{\circ} \mathrm{C}$ ) which gives credit to the previous suggestion of a sharper phase separation when PMMA is substituted for PS. $T_{\mathrm{g}} 1$ of HA4 remains unmodified upon stereocomplexation of the sPMMA blocks (CHA4), indicating that the PEB matrix is unaffected by stereocomplexation, in agreement with the d.s.c. analysis. The $\tan \delta$ value at $T_{\mathrm{g}} 1$ for CHA4 is lower compared to the parent copolymer HA4 due to the reduction in the soft phase content when iPMMA is added. A great difference is observed for samples CHA4 and HA4 in the upper transition temperature. Indeed the loss tan $\delta$ of HA4 starts to increase at $c a 100^{\circ} \mathrm{C}$ (Figure $10 B$ ) and reaches a maximum at $135^{\circ} \mathrm{C}$, whereas it starts to increase at a higher temperature $\left(\mathrm{c} a 130^{\circ} \mathrm{C}\right)$ in the case of CHA4 and no maximum of $\tan \delta$ is observed until $160^{\circ} \mathrm{C}$. The modulus in the glassy and the rubbery plateau regions (Figure $10 \mathrm{~A}$ ) is systematically higher for sample CHA4 compared to HA4 and A4, possibly due to the higher PMMA content and the formation of semi-continuous hard phases.

Figure 11 shows the dynamic mechanical properties for the MSBSM pentablock A6 and the hydrogenated counterpart HA6. Although this copolymer contains three components, only two transitions are clearly observed, one at low temperature for the rubbery phase, and the other one at high temperature for the hard phase. It is worth pointing out that the loss tan $\delta($ Figure $11 B)$ starts to increase at $c a 70^{\circ} \mathrm{C}$ compared to $100^{\circ} \mathrm{C}$ for the $\mathrm{MBM}$ triblock (Figure 10B). This difference is thought to be the signature of the PS relaxation in agreement with a $T_{\mathrm{g}}$ smaller than sPMMA by $\mathrm{ca} 20^{\circ} \mathrm{C}$. The loss peak at $T_{\mathrm{g}} 2$ indicates a more important damping for the hydrogenated sample HA6 than the parent copolymer A6, which would suggest a sharper phase separation in HA6, although $T_{\mathrm{g}} 2$ is quite comparable for the two samples. Any explanation would be speculative as long as the detailed phase morphology is unknown.

In the case of PtBMA containing triblock copolymers, $T_{\mathrm{g}} 2$ is too diffuse to be recorded accurately by d.s.c. Figure 12 shows the dynamic mechanical behaviour of the sample B and the hydrogenated counterpart HB. The temperature dependence of $\tan \delta$ clearly shows two transitions (Figure 12B), which confirms the two-phase structure of these materials. In contrast to the MBM and SBS samples in which the upper service temperature is increased upon hydrogenation, $T_{\mathrm{g}} 2$ of the PtBMA domains actually decreases upon hydrogenation. Furthermore, the loss peak at $T_{\mathrm{g}} 1$ for the hydrogenated sample HB shows a strongly reduced damping compared to sample B. Although only $T_{\mathrm{g}} 1$ is detected by d.s.c. for the PIBMA containing triblock copolymers, two transitions are clearly observed by dynamic mechanical analysis, as shown in Figure 13. $G^{\prime}$ is again larger in the rubbery plateau for the hydrogenated sample $\mathrm{HC}$ compared to the parent copolymer $\mathrm{C}$, and this difference is as pronounced as the temperature is high. 
The $\tan \delta$ at $T_{\mathrm{g}} 2$ is much broader for the original copolymer $\mathrm{C}$, which indicates a larger distribution of the relaxation times for the hard phase. Furthermore, $T_{g} 2$ for sample $\mathrm{C}$ is much lower than $\mathrm{HC}$. All these characteristic features are consistent with some phase mixing in the unsaturated copolymer $\mathrm{C}$, which is drastically decreased by hydrogenation of the PBD component.

Stress-strain behaviour

Tensile properties of the original block copolymers, hydrogenated counterparts and stereocomplexes with iPMMA are reported in Table 4 and Figure 14.

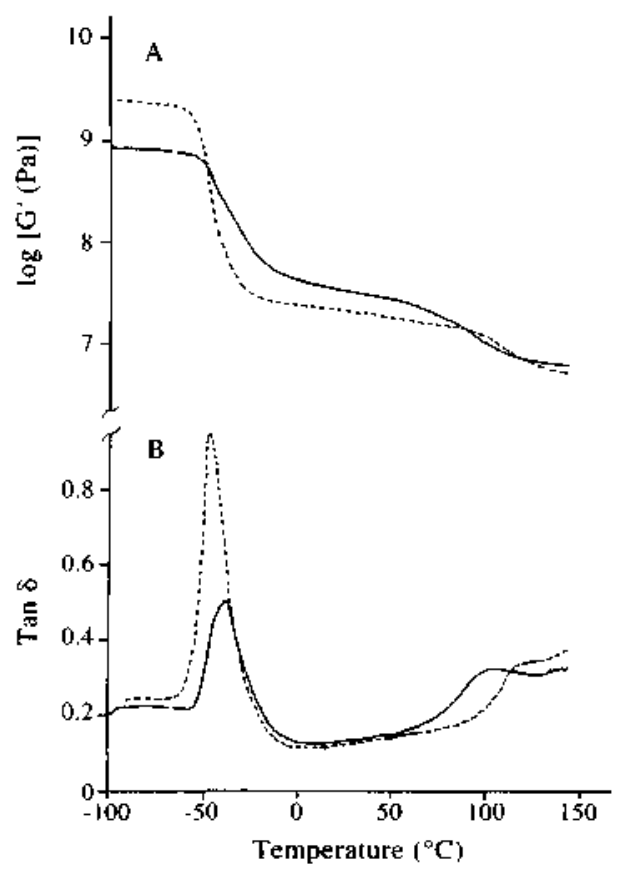

Figure 12 Shear storage modulus $\left(G^{\prime}\right)(A)$ and loss tan $\delta\left(=G^{\prime \prime} / G^{\prime}\right)(B)$ at $1 \mathrm{~Hz}$ for the $t B M A-B D$ - $t B M A$ sample $B$ (- - -) and the hydrogenated counterpart $H B(-)$
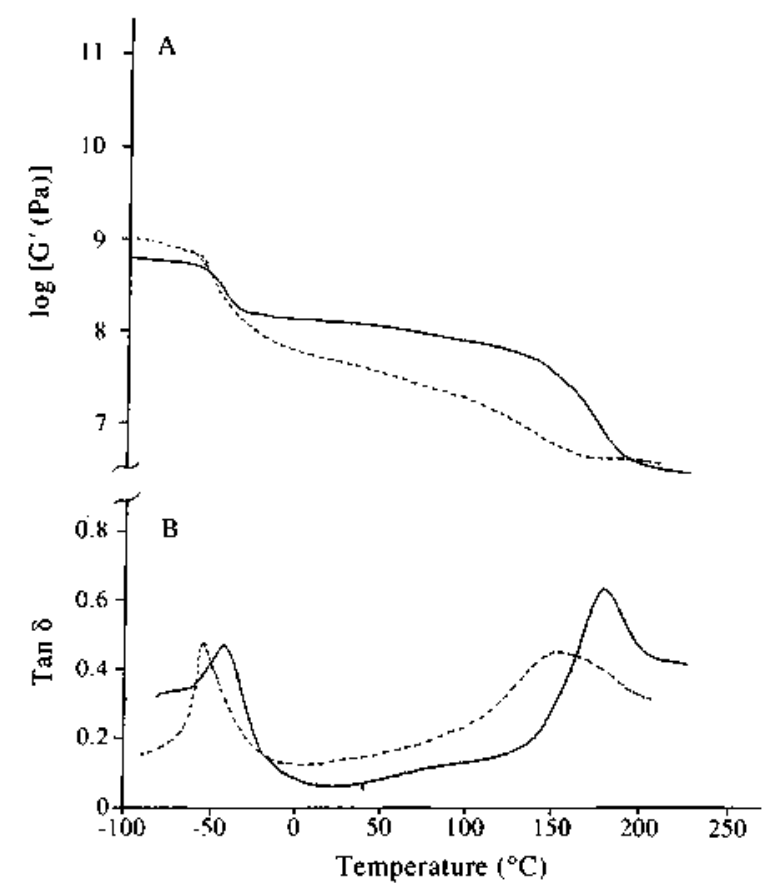

Figure 13 Shear storage modulus $\left(G^{\prime}\right)(A)$ and loss tan $\delta\left(=G^{\prime \prime} / G^{\prime}\right)(B)$ at 1 Hz for the IBMA-BD-IBMA sample 
C (- - -) and the hydrogenated counterpart HC (-)

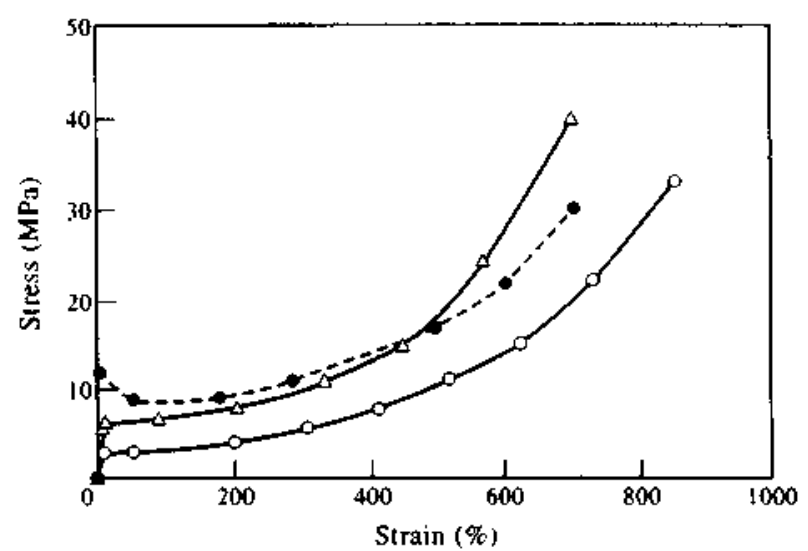

Figure 14 Stress-strain curves at room temperature for the MBM triblock copolymer A4 (०), the hydrogenated

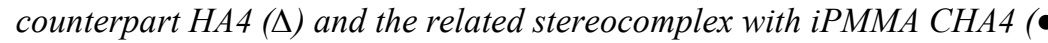
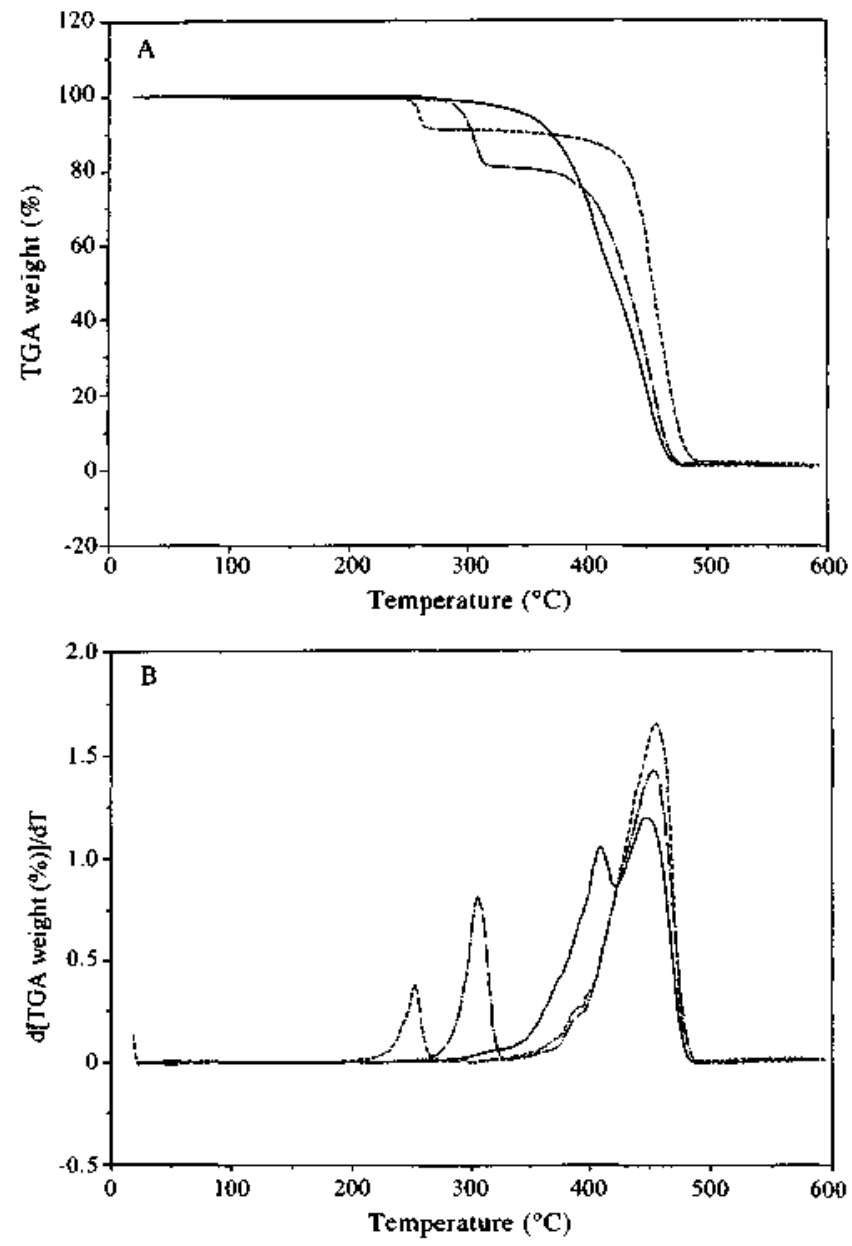

Figure 15 Weight loss $(A)$ and differential weight loss $(B)$ as a function of temperature at a heating rate of $10^{\circ} \mathrm{C} \mathrm{min}^{-1}$, for samples HA4 (-), HB (- - -) and HC (- - -) 
Table 4 Mechanical properties of hydrogenated block copolymers and related blends with iPMMA

\begin{tabular}{|c|c|c|c|c|}
\hline Sample & Yield stress (MPa) & $\begin{array}{l}\text { Tensile strength }(\mathrm{MPa}) \\
\left(\sigma_{\mathrm{b}}\right)\end{array}$ & $\begin{array}{l}\text { Elongation at break } \\
(\%)\left(\varepsilon_{\mathrm{b}}\right)\end{array}$ & $\begin{array}{l}\text { Permanent set }{ }^{a} \text { at break } \\
(\%)\end{array}$ \\
\hline$\overline{\mathrm{Al}}$ & - & 26 & 1000 & 30 \\
\hline $\mathrm{A} 2$ & - & 28 & 1000 & 30 \\
\hline A3 & 4 & 31 & 950 & 38 \\
\hline A4 & 5 & 33 & 850 & 57 \\
\hline A5 & 10 & 34 & 500 & 110 \\
\hline A6 & 4 & 25 & 900 & 100 \\
\hline B & - & 24 & 1040 & 12 \\
\hline $\mathrm{C}$ & 2 & 30 & 1000 & 40 \\
\hline HA1 & - & 30 & 900 & 43 \\
\hline HA2 & - & 32 & 800 & 45 \\
\hline HA3 & 7 & 38 & 750 & 80 \\
\hline HA4 & 6 & 40 & 700 & 96 \\
\hline HA5 & 15 & 26 & 370 & 130 \\
\hline HA6 & 8 & 28 & 620 & 180 \\
\hline CHA4 & 12 & 30 & 700 & 210 \\
\hline HB & - & 22 & 900 & 20 \\
\hline $\mathrm{HC}$ & 5 & 33 & 560 & 50 \\
\hline
\end{tabular}

${ }^{a}$ Ratio of irreversible deformation to the initial length of the sample at break

For MBM triblock copolymers, the tensile properties depend on molecular weight and PMMA content [23], the ultimate tensile strength generally increases with increasing molecular weight and PMMA content [23]. In the A1 to A5 series of MBM samples (Table 1), the ultimate tensile properties are the same for A1 and A2 that have comparable PMMA content ( $c$ a 27\%) and molecular weight. These properties change when the A3 and A4 samples of a higher PMMA content $(37 \%)$ are considered. These copolymers show higher ultimate tensile strength $\left(\sigma_{\mathrm{b}}\right)$ and permanent set at break and smaller elongation at break $\left(\varepsilon_{\mathrm{b}}\right)$ compared to A1 and A2. These effects are more pronounced for A4 due to a higher molecular weight than A3 (128 000 vs 92000). Finally, further increase in PMMA content (50\%) and molecular weight (200000) (sample A5) mainly results in a significant decrease in $\varepsilon_{\mathrm{b}}$ and increase in the permanent set at break. When the PMMA content reaches $37 \%$ and higher, a yielding is observed which is the signature of a semi-continuous hard phase. The yield stress expectedly increases with the PMMA content (from A3, A4 to A5). The tensile properties are significantly affected by hydrogenation of the PBD midblocks, as shown in Table 4 and Figure $14 . \sigma_{\mathrm{b}}$ is increased except for the sample HA5 of the highest PMMA content (50\%). The higher $\sigma_{\mathrm{b}}$ reported for SEBS compared to SBS has been accounted for by a better phase separation [8]. The same explanation is reasonable for the MEBM copolymers compared to MBM, as confirmed by the d.s.c. and d.m.a. analysis previously discussed. The yield stress and the permanent set at break are also increased upon hydrogenation, whereas $\varepsilon_{\mathrm{b}}$ is decreased. Stereocomplexation of MEBM with iPMMA decreases the $\sigma_{\mathrm{b}}$, while keeping the $\varepsilon_{\mathrm{b}}$ unchanged (see HA4 and CHA4 in Figure 14 and Table 4), which agrees with the previously reported behaviour for the stereocomplexation of the MBM copolymers by iPMMA [7]. That a semi-crystalline hard phase is now continuous is consistent with a higher yield stress and a pronounced necking for $\mathrm{CHA} 4$, together with a larger permanent set at break. It is worth noting that no stress whitening is observed for this transparent sample during necking, which suggests that shear yielding might be the major energy-absorbing mechanism rather than crazing in this semi-crystalline material. Comparison of the tensile properties for the MSBSM pentablock copolymer A6 and the hydrogenated counterpart HA6 (Table 4) shows no significant difference with respect to the MBM triblocks.

When PtBMA is substituted for PMMA in triblock copolymers containing triblock copolymers, all the other characteristic features being the same (27\% hard block and 95000 molecular weight), sample B differs from A1 by an improved permanent set at break (Table 4). When the hydrogenated counterparts (HA1 and HB1) are compared, in addition to a much smaller permanent set at break, $\sigma_{\mathrm{b}}$ of $\mathrm{HB}$ is much smaller than HA1, possibly due to a less sharp phase separation as shown by d.m.a.

Tensile properties of the PIBMA containing triblock copolymer $(\mathrm{C})$ are not significantly different from the parent MBM triblock (A3). The hydrogenation of $\mathrm{C}$ results in a larger decrease in $\varepsilon_{\mathrm{b}}$ but in a much smaller increase in permanent set at break compared to $\mathrm{A} 3$. 


\section{Thermogravimetric analysis (t.g.a.)}

Thermostability of various saturated block copolymers has been investigated by t.g.a. Figure 15 illustrates the typical weight loss (Figure $15 \mathrm{~A}$ ) and its derivative (Figure 15B) as a function of temperature under a nitrogen atmosphere for triblock copolymers containing different methacrylate end blocks. Thermal degradation proceeds in two main steps whatever the samples. In reference to the thermal stability of homopolymethacrylates [24] and $\mathrm{PEB}$, it appears that the polymethacrylate component is degraded at the lower temperature. Actually, PtBMA and PIBMA are degraded in two steps [17, 25].

The bulky tertiary-butyl and isobornyl groups, which accounts for 40 and $62 \mathrm{wt} \%$ in PtBMA and PIBMA, respectively, starts to be degraded at 200 and $250{ }^{\circ} \mathrm{C}$, respectively, with formation of anhydride groups which degrade simultaneously to PEB. The thermostability of the hydrogenated triblocks is dictated by the outer block in the following order MEBM > IBMA-EB-IBMA > tBMA-EB-tBMA.

\section{CONCLUSION}

Triblock and pentablock copolymers containing a central PBD block and polyalkylmethacrylate outer blocks have been synthesized and hydrogenated with formation of well defined saturated thermoplastic elastomers. Methylmethacrylate, $t$-butylmethacrylate or isobornylmethacrylate have been used as precursors of the end block, which are completely stable under the conditions used for the hydrogenation reaction. Whatever the initiator used for the butadiene polymerization (monofunctional vs difunctional), the ethylene and the butylene units formed upon hydrogenation are randomly distributed in the PEB block.

The content of 1,2-units of the original PBD block is $c a 45 \%$ and hydrogenation of this midblock results in a soft phase containing poorly organized crystalline domains whatever the copolymers. The effect of hydrogenation on the phase separation depends on the outer block. The phase separation is moderately enhanced by hydrogenation for PMMA containing copolymers, it is more significantly increased in case of PIBMA hard blocks, whereas it is slightly decreased for PtBMA containing copolymers.

Stereocomplexation occurs when the MEBM copolymers are blended with isotactic PMMA as it was the case for the MBM precursors. The ultimate tensile strength is generally increased when the phase separation is improved by hydrogenation, in contrast to the elongation at break which is decreased. The thermal stability of the hydrogenated block copolymers depends on the polyalkylmethacrylate outer block, the order of thermostability under a nitrogen atmosphere being MEBM > IBMA-EB-IBMA > tBMA-EB-IBMA.

\section{ACKNOWLEDGEMENTS}

The authors are very much indebted to the IWT (Flemish Institute for the Promotion of Science-Technological Research in Industry) for the financial support of a joint research program with Raychem N.V. (Kessel-Lo, Belgium) and the Katholieke Universiteit Leuven (Prof. H. Berghmans and H. Reynaers). They warmly thank Dr N. Overbergh (Raychem, Kessel-Lo), Dr Ph. Hammond and Dr J. Hudson (Raychem Swindon) for stimulating discussions. They are grateful to the "Services Fédéraux des Affaires Scientifiques, Techniques et Culturelles" for general support in the frame of the "Poles d'Attraction Interuniversitaires: Polymères". Ph. Dubois is research associate of the Belgian National Fund for Scientific Research (FNRS).

\section{REFERENCES}

[1] Fetters, L. J. and Morton, M., Macromolecules, 1969, 2, 453

[2] Morton, M. and Mikesell, S. L., J. Macromol. Sci-Chem., 1993, A7, 1391.

[3] Ladd, B. J. and Hogen-Esch, T. E., Polym. Prepr., 1989,30,261.

[4] Long, T. E., Broske, A. D., Bradley, D. J. and McGrath, J. E., J. Polym. Sci. Polym. Chem., 1989, $27,4001$.

[5] Morton, M., Research on anionic triblock copolymers, in Thermoplastic Elastomers, ed. N. R. Legge, G. Holden and H. E. Schroeder.

Hauser, Munich, 1987, p. 67.

[6] Schomaker. E. and Challa, G., Macromolecules, 1988, 21, 3506, 2195.

[7] Yu, J. M., Yu, Y., Dubois, Ph., Teyssié Ph. and Jerome, R., Polymer, in press.

[8] Gergen, W. P., Lutz, R. G., Darison, S. in Thermoplastic Elastomers, ed. N. R. Legge, G. Holden and H. E. Schroeder. Hauser, Munich, 1987, p. 507.

[9] Pendleton, J. F. and Hoeg, D. F., Adv. Chem. Ser., 1972,129,27.

[10] Rachapudy. H., Smith, G. G., Raju, V. R. and Graessley, W. W, J. Polym. Sci. Polym. Phys., 1979, $17,1211$.

[11] Schulz, D. N., in Encyclopedia of Polymer Science and Technology, Vol. 7,2nd edn, ed. H. F. Mark. Wiley-Interscience, New York, 1987 , p. 807.

[12] Roy, S., Bhattacharjee and Gupta, B. R., J. Appl. Polym. Sci., 1993,49,375.

[13] McManus, N. T. and Rempel, L. J. M. S., Rev. Macromol. Chem. Phys., 1995, C35, 239.

[14] Yokota, K. and Hirabayashi, T., Polym. J., 1981, 13, 813.

[15] Auschra, C. and Stadler, R., Polym. Bull., 1993, 30, 257. 
[16] Ren, Q., Zhang, H. J., Zhang, X. K. and Huang, B. T., J. Polym. Sci. Polym. Chem.. 1993, $31,847$.

[17] Long, T. E., Allen, R. D. and McGrath. J. E., Polym. Prepr., 1986, 27(2), 54.

[18] Imoto, M., Otsu, T., Tsuda, K. and Ito, T., J. Polym. Sci. A, 1964, 1407.

[19] Cowie, J. M. G., Lath, D. and McEwen, I. J., Macromolecules, 1979, 12, 53.

[20] Gilman, H. and Cartledge, F. K., J. Organomet. Chem.. 1964, 2, 447.

[21] Long, T. E., Allen, R. D., McGrath, J. E., in Recent Advances in Mechanistic and Synthetic Aspects of Polymerization, ed. M. FontanilleandA.Guyot.NATOASIser., 1987. Vol. 215, p. 79.

[22] Clague, A. D. H., van Broekhoven, J. A. M. and Blaauw, L. P., Macromolecules, 1974, 7, 348.

[23] Yu, J. M., Dubois, Ph., Jérôme, R. and Teyssié. Ph., Macromolecules, 1996, 29, 6090.

[24] Chiantore, O., Guaita, M. and Rendina, G., Makromol. Chem., 1989, 190, 449.

[25] Matsumoto, A., Mizuta, K. and Otsu, T., J. Polym. Sci. Polym. Chem., 1993, 31,2531,

[26] Yu. Y., Dubois, Ph., Jérôme, R. and Teyssié. Ph., J. Polym. Sci. Polym. Chem., 1996, 34, 2221.

[27] Doi, Y, Yano, A., Soga, K. and Burfield, D. R., Macromolecules, 1986. 19, 2409.

[28] Antkowiak, T. A., Oberster, A. E., Halasa, A. F. and Tate, D. P., J. Polym. Sci., A, 1972, 1319.

[29] Yu, Y., Dubois, Ph., Jérôme, R. and Teyssié, Ph., Macromolecules, 1996, 29, 1753, 2738. 